\title{
Papers
}

\section{Impact of counselling on careseeking behaviour in families with sick children: cluster randomised trial in rural India}

Pavitra Mohan, Sharad D Iyengar, Jose Martines, Simon Cousens, Kalpana Sen

\begin{abstract}
Objective To assess whether training doctors in counselling improves careseeking behaviour in families with sick children. Design Pair matched, community randomised trial conducted in 12 primary health centres (six pairs). Doctors in intervention centres were trained in counselling, communication, and clinical skills, using the integrated management of childhood illness approach.

Setting Rural district in Rajasthan, India.

Participants Children aged under 5 years presenting for curative care and their mothers were recruited and visited monthly at home for six months. A total of 2460 children were recruited (1248 intervention, 1212 control).

Main outcome measures Careseeking behaviour of mothers for sick children; mothers' knowledge and perceptions of seeking care; counselling performance of doctors.

Results For episodes of illness with at least one reported danger sign, $15 \%$ of intervention group mothers and $10 \%$ of control group mothers reported having sought care from an appropriate provider promptly; this difference was not statistically significant (relative risk reduction 5\%, 95\% confidence interval $-0.4 \%$ to $11 \% ; \mathrm{P}=0.07$ ). One month after training, intervention site doctors counselled more effectively than control group doctors, but at six months their performance had declined. A greater proportion of mothers in the intervention group than in the control group recalled having had at least one danger sign explained $(45 \% v 8 \% ; \mathrm{P}=0.02)$.

Conclusions Mothers' appreciation of the need to seek prompt and appropriate care for severe episodes of childhood illness increased, but their careseeking behaviour did not improve significantly.
\end{abstract}

\section{Introduction}

Delays in seeking appropriate care, and not seeking care at all, contribute to the large number of child deaths in developing countries. ${ }^{1-4}$ Existing interventions could prevent many deaths in children if they presented for appropriate and timely care. ${ }^{5}$ Improving families' careseeking behaviour could contribute significantly to reducing child mortality in developing countries. The World Health Organization estimates that seeking prompt and appropriate care could reduce child deaths due to acute respiratory infections by $20 \% .{ }^{6}$

The integrated management of childhood illnesses (IMCI) strategy, besides improving providers' skills in managing childhood illnesses, aims to improve families' careseeking behaviour. Health workers are trained to teach mothers about danger signs and counsel them on the need to seek care promptly if these signs occur.?
Interventions to improve careseeking have been proposed, but their impact has not been evaluated. This trial assessed whether training healthcare providers in counselling and communication improves the careseeking behaviour of families that subsequently consult them.

\section{Subjects and methods}

Study population

Udaipur, a district in Rajasthan, India, has a population of 2.6 million, $80 \%$ of which is rural. Only $44 \%$ of women are literate. ${ }^{8}$ The public health system comprises 92 primary health centres and 538 subcentres, with a tertiary referral hospital in Udaipur city. Curative services at primary health centres are provided primarily by doctors; auxiliary nurse midwives provide preventive services such as immunisation and antenatal care.

\section{Sampling and randomisation}

We used the integrated management of childhood illness strategy in a community randomised trial of training in counselling. Our sampling frame comprised 29 primary health centres where a doctor lived in the village. We randomly selected six centres from this list and matched each as closely as possible with a centre with similar caseload, location (rural or periurban), and socioeconomic status of catchment population. For each pair of primary health centres, we allocated one centre to the intervention arm by drawing names from a box.

\section{Intervention}

Using the standard guidelines, ${ }^{9}$ we adapted the generic training modules of the integrated management of childhood illness strategy, strengthening the sections on counselling and communication with material from the breastfeeding counselling training course prepared by WHO and Unicef. ${ }^{10}$ We used the guidelines on rapid identification of local terminology to identify local terms for illnesses and danger signs. ${ }^{9}$

Doctors at intervention sites underwent a five day training programme covering counselling, communication, and clinical skills. They were trained to teach mothers about signs indicating serious illness (box) and to counsel them on the need to seek care promptly if these signs occur. A card with pictures and messages (child health card; see bmj.com) was developed to assist in counselling and copies of these cards were given to intervention site doctors to distribute to mothers. Control site doctors were trained over a period of one to three days in clinical skills alone. 


\section{Recruitment and data collection}

At each primary health centre we aimed to recruit 200 mothers bringing children aged under 5 years for curative care. Project staff (one at each site) began enrolment on 1 January 2002. At five intervention and four control sites we were able to enrol close to the required number of children within three months, but in the remaining sites we had to extend the recruitment period to as much as six months to recruit the required number of children.

About one month after enrolment a trained field worker made an initial follow up home visit to collect social, economic, and demographic information. The mother (or the person who accompanied the child to the doctor) was asked to recall their interaction with the doctor during the visit when they were enrolled in the study. In addition, the mother was presented with three scenarios concerning sick children who had danger signs, and we asked her views on appropriate responses in such situations. At this visit, and at five subsequent monthly visits, we used standard questions, supplemented by open narratives, to ask mothers about episodes of illness during the previous month, the care sought, and the treatment given.

The precise objectives of the study were not disclosed to the doctors or field workers: they were told that the study aimed to assess children's illness load and how families respond to illness. Field workers provided similar information to the families when seeking their consent.

\section{Sample size calculations}

The study was designed to detect an absolute difference of $20 \%$ in the proportion of occasions when mothers sought appropriate care for children with danger signs. We assumed that children at the study sites would have an average of 0.2 episodes of illness with a danger sign over the six months of follow up and that control group mothers would seek appropriate care for their children in $35 \%$ of episodes with danger signs. ${ }^{11}$

Assuming a design effect of 2, we estimated that 1060 children would be needed in each group to provide $80 \%$ power at the $5 \%$ significance level. Allowing for $10 \%$ losses to follow up, we planned to recruit 1160 children in each group.

\section{Data collection}

One and six months after training, we observed each doctor in 10 consultations with children and recorded details of their counselling performance.

\section{Data analysis}

Data were double entered, and validation and consistency checks were performed weekly. We used Stata version 7 for analysis. Mothers' knowledge of care seeking, recall of counselling messages, responses to hypothetical scenarios, and care seeking practices were compared between the two groups. To measure the impact of the intervention, we estimated the relative risk reduction for each outcome. Thus an impact of $10 \%$ on care seeking indicates a 10\% reduction in the number of occasions when mothers did not seek care. Point estimates were obtained using the generalised estimating equations approach with an

Signs indicating serious illness

- Rapid breathing

- Refusal to breastfeed or drink

- Blood in stools

- Vomiting everything

- Lethargy exchangeable correlation structure to allow for within cluster correlation. To obtain robust $95 \%$ confidence intervals for these estimates we performed unpaired $t$ tests on cluster (primary health centre) level data ${ }^{12}$ and used the results of these tests to obtain test based confidence intervals. ${ }^{13}$

\section{Ethical aspects}

At the time of recruitment at the clinic, the study was explained to the mother and permission was sought to visit her at home. At the first household visit, an information sheet explaining the nature of the study, the likely time required for each visit, confidentiality, and the absence of any incentives or harm was read out. Mothers who consented to participate were recruited into the study.

\section{Results}

Of 2460 eligible children seen at primary health centres, at least one follow up home visit was completed for 2280 (93\%; range 89 to 258 per centre). Follow up was similar in the intervention and control groups (1163/1248, 93\%, and 1117/1212, 92\%). Of children completing at least one visit, $894(77 \%)$ in the intervention and $914(82 \%)$ in the control group completed all six visits (fig 1). The mean numbers of completed visits were 5.5 in the intervention and 5.6 in the control group.

Children in the intervention group were slightly younger than those in the control group (mean $1.26 v 1.44$ years) (table 1). A higher proportion of intervention children came from the scheduled caste or tribes. Mothers in the intervention group were less likely to be literate than their control counterparts, but tended to be less poor. Control children lived further away from the primary care facility at which they were enrolled but were more likely to have been born in a hospital than the intervention children. (When possible, we controlled for these characteristics in analyses of the impact of the intervention.) Immunisation coverage, median number of live children, experience of previous child death, and presence of the father in the household were similar in the two groups.

\section{Impact of the intervention}

\section{Doctors' counselling performance}

One month after training, doctors in the intervention group performed better on all the measured aspects of performance (table 2). They counselled the mothers more often concerning feeding and careseeking and asked open ended questions to check their understanding more often than doctors in the control group. They also seemed to perform better with respect to other aspects of communication, though observed differences were compatible with chance. Six months after training, the performance of the intervention group on several behaviours had declined substantially (fig 2).

\section{Mothers'recall of counselling}

At the first follow up home visit, mothers were asked about their interaction with the doctor during the consultation. More mothers in the intervention group than in the control group reported that the doctor had explained one or more target signs (table 3). A high proportion reported that the doctor had given them a child health card, and most of them could produce the card.

\section{Mothers'perceptions of appropriate care}

At the first follow up visit, mothers were also presented with three scenarios concerning sick children with danger signs, and asked to indicate what they would do in such circumstances. 


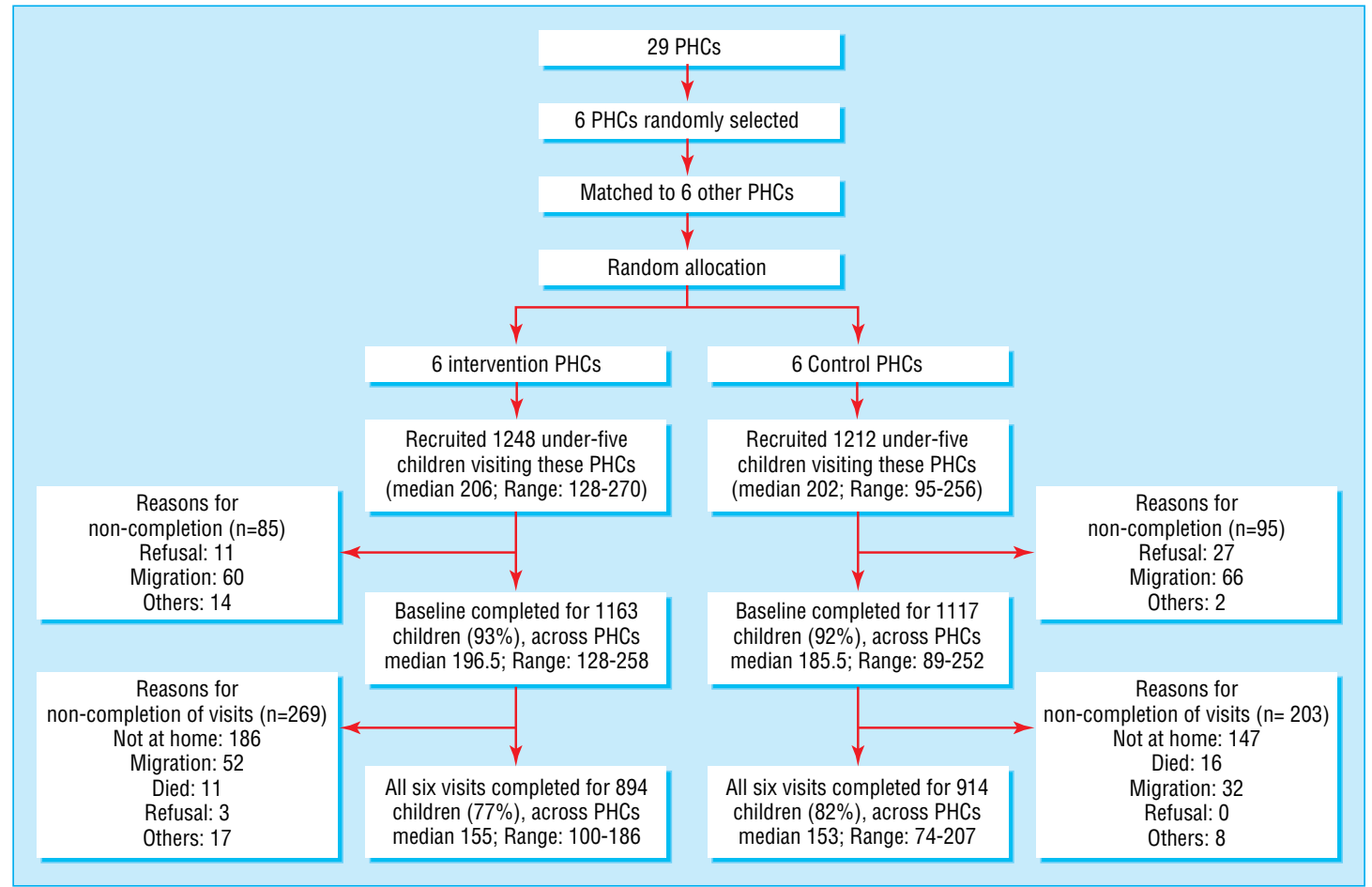

Fig 1 Flow of participants through trial. $\mathrm{PHC}=$ primary health centre

Intervention group mothers indicated more often than control group mothers that they would seek care from an appropriate

Table 1 Baseline social, economic, family, and demographic characteristics. Values are numbers (percentages) of children unless stated otherwise

\begin{tabular}{|c|c|c|}
\hline Characteristics & $\begin{array}{l}\text { Intervention group } \\
\quad(\mathrm{n}=1163)\end{array}$ & $\begin{array}{c}\text { Control group } \\
(\mathrm{n}=1117)\end{array}$ \\
\hline \multicolumn{3}{|l|}{ Child } \\
\hline \multicolumn{3}{|l|}{ Age (years): } \\
\hline 0 & $429(37)$ & $358(32)$ \\
\hline 1 & $303(26)$ & $281(25)$ \\
\hline 2 & $214(18)$ & $218(20)$ \\
\hline 3 & $135(12)$ & $143(13)$ \\
\hline 4 & $82(7)$ & $117(10)$ \\
\hline Boys & $719(62)$ & $678(61)$ \\
\hline Scheduled caste or tribes & $330(28)$ & $258(23)$ \\
\hline $\begin{array}{l}\text { Complete immunisation coverage } \\
\text { (among children 12-23 months) }\end{array}$ & $120 / 303(40)$ & $112 / 281(40)$ \\
\hline \multicolumn{3}{|l|}{ Mother } \\
\hline \multicolumn{3}{|l|}{ Years of schooling: } \\
\hline Illiterate & $485(42)$ & $526(47)$ \\
\hline $1-7$ & $70(6)$ & $59(5)$ \\
\hline $8-11$ & $198(17)$ & $168(15)$ \\
\hline$\geq 12$ & $410(35)$ & $364(33)$ \\
\hline Experienced loss of child & $199(17)$ & $197(18)$ \\
\hline $\begin{array}{l}\text { Median number of live children } \\
\text { (interquartile range) }\end{array}$ & $2(1-3)$ & $2(1-3)$ \\
\hline \multicolumn{3}{|l|}{ Family } \\
\hline Index child delivered in hospital & $517(44)$ & $565(51)$ \\
\hline $\begin{array}{l}\text { Median (interquartile range) distance to } \\
\text { primary health centre (mins) }\end{array}$ & $15(10-30)$ & $20(10-35)$ \\
\hline Father lives with family & $917(79)$ & $854(76)$ \\
\hline Alternative caregiver while mother works & $572(49)$ & $586 \quad(52)$ \\
\hline \multicolumn{3}{|l|}{ Socioeconomic group (by quartile): } \\
\hline Lowest & $256(22)$ & $314(28)$ \\
\hline Second & $286(25)$ & $287(26)$ \\
\hline Third & $287 \quad(25)$ & 262 (23) \\
\hline Highest & 334 (29) & 254 (23) \\
\hline
\end{tabular}

provider promptly (29\% of 3420 scenarios $v 12 \%$ of 3330 scenarios; $\mathrm{P}=0.005$ ).

\section{Careseeking behaviour}

During the follow up period, 2851 episodes of child illness were reported by mothers in the intervention group and 2654 in the control group (mean 2.45 in intervention group $v 2.38$ in control group). In a high proportion of these episodes mothers in both groups reported seeking care outside the home (table 4). In about half of all episodes, the child was reported to have been taken to the primary health centre or another appropriate provider. Intervention group mothers reported seeking care from an appropriate provider promptly (within 24 hours of recognition of the illness) more often than control group mothers $(\mathrm{P}=0.02)$.

Mothers in both groups reported the presence of one or more danger signs in 19\% of all illness episodes (intervention group 543, control group 513). Intervention group mothers perceived 49\% (268) of these illness episodes as serious and control group mothers perceived $41 \%(210)$ as serious $(\mathrm{P}=0.26)$. Mothers in both groups reported seeking care outside the home in more than $90 \%$ of these episodes. A higher proportion of intervention group mothers reported seeking care from an appropriate provider than control group mothers (65\% (353) v 57\% (290); $\mathrm{P}=0.03$ ) and reported seeking appropriate care promptly (15\% (84) v 10\% (51); $\mathrm{P}=0.07)$.

\section{Discussion}

Mothers attending primary health centres in the intervention arm were more likely to recall messages and identify an appropriate course of action for children's illnesses. Responses of mothers in the intervention group to hypothetical scenarios indicates that counselling by trained providers influenced the perceived efficacy of facility based treatment and mothers' 
Table 2 Communication and counselling performance of doctors one month after training. Values are numbers (percentages) of doctors unless stated otherwise

\begin{tabular}{|c|c|c|c|c|}
\hline Components absent in consultation & Intervention group $(\mathrm{n}=60)$ & Control group $(n=60)$ & Relative risk reduction* $(\%)(95 \% \mathrm{Cl})$ & $P$ value† \\
\hline Doctor did not greet the mother & $7(12)$ & $17(28)$ & 58 (-101 to 92) & 0.24 \\
\hline Doctor did not use local dialect & $1(2)$ & $11(18)$ & 91 (-298 to 100$)$ & 0.19 \\
\hline Doctor did not play with child & $17(28)$ & $38(63)$ & $55(-1$ to 79$)$ & 0.05 \\
\hline Doctor did not praise mother & $36(60)$ & $59(98)$ & $39(-7$ to 65$)$ & 0.08 \\
\hline Doctor did not ask open ended checking questions & $50(83)$ & $60(100)$ & 17 (2 to 29) & 0.03 \\
\hline Doctor did not explain any danger signs & $19(32)$ & $47(78)$ & 60 (5 to 83$)$ & 0.04 \\
\hline Doctor did not advise on feeding & $39(65)$ & $57(95)$ & 32 (1 to 53) & 0.04 \\
\hline Doctor did not check child's immunisation status & $8(13)$ & $53(88)$ & 85 (71 to 92$)$ & $<0.0001$ \\
\hline
\end{tabular}

*Relative risk reduction $=(1-$ risk ratio $) \times 100 \%$.

†Based on $t$ test at the health facility level.

knowledge of when to seek care promptly. Evidence that the intervention improved mothers' appreciation of severity is weak.

\section{Improving careseeking behaviour}

Previous studies have shown that recognition of illness, perceiving the illness as one that is amenable to treatment at health facilities, appreciating the severity of the illness, and having access to good quality services influence whether caretakers seek appropriate and timely care..$^{13-17}$ On the basis of these studies, various strategies have been proposed to improve careseeking behaviour including improving access, educating families to recognise illness and appreciate severity, and improving quality of care. ${ }^{18}{ }^{19}$ However, few studies have measured the impact of these strategies on caretakers' behaviour.

After integrated management of childhood illness training in Ethiopia, in $60 \%$ of observed consultations the health workers explained to parents the circumstances under which they should return immediately to the health facility. ${ }^{20}$ This study did not

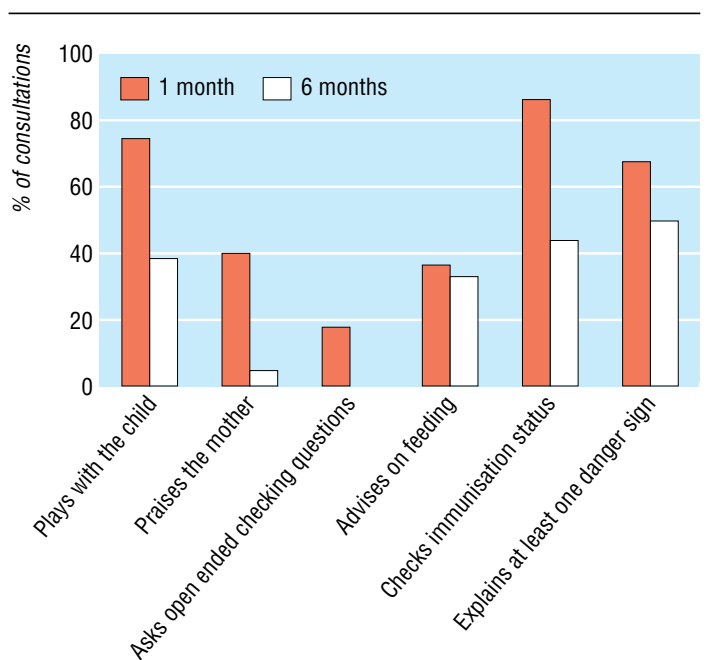

Fig 2 Counselling performance of intervention doctors at one month and six months report on counselling given before doctors received training, nor on mothers' compliance with this advice.

Although the impact of counselling interventions on careseeking behaviour has not been rigorously evaluated previously, there is evidence that such interventions can improve other health related practices. Santos et al have reported an impact of nutrition counselling by doctors on feeding practices and anthropometric indices of young children in urban Brazil. ${ }^{21}$

\section{Changes in knowledge}

Some improvements in careseeking practices seem to have resulted from improved knowledge about when to seek care and improved perceptions of the severity of the illness. More generally, doctors' improved communication skills may have increased families' readiness to seek care. However, even after the intervention, only $15 \%$ of episodes with a danger sign led to prompt and appropriate care seeking. Why did changes in knowledge and perceptions not translate into greater improvements in practice? Firstly, the intervention had little impact on recognition of illness or of specific danger signs: mothers in the two groups reported almost equal numbers of illness episodes and equal proportions of episodes that involved danger signs. Secondly, the intervention did not impact on other constraints to seeking care, such as access to and cost of treatment. Thirdly-and importantlyalthough counselling by responsive and skilled providers during one encounter may be sufficient to improve knowledge and perceptions, changes in behaviour may require prolonged exposure to the educational messages.

\section{Doctors' performance}

The decline in performance of the intervention group doctors in counselling by the end of the six month study period is of concern. Informal discussions with the doctors indicated that, faced with a variety of field and administrative duties, they have little time for clinical duties and hence little time for counselling. Some doctors reported that poor organisation of the flow of patients results in patients crowding around them at times, making it difficult to counsel individual caretakers. Achieving sustained changes in the counselling provided in settings such as ours is likely to require not only monitoring and ongoing train-

Table 3 Mothers' recall, at one month, of counselling by doctors during initial consultation. Values are numbers (percentages) unless otherwise stated

\begin{tabular}{|c|c|c|c|c|}
\hline Mother's recall of messages & Intervention group $(\mathrm{n}=1063)$ & Control group $(n=1048)$ & Adjusted relative risk reduction (\%) $(95 \% \mathrm{Cl})$ & $P$ value \\
\hline Doctor did not advise mother when to return & $530(50)$ & $720(69)$ & 30 (-28 to 61) & 0.22 \\
\hline Doctor did not explain any of the danger signs & $588(55)$ & $965(92)$ & 41 (8 to 61 ) & 0.02 \\
\hline Mean number of danger signs explained & 0.87 & 0.07 & & 0.01 \\
\hline Doctor gave the mother card & $881(83)$ & NA & & \\
\hline Used card for explaining danger signs & $491(46)$ & NA & & \\
\hline Mother could produce the card at 1 month & $836(79)$ & NA & & \\
\hline
\end{tabular}


Table 4 Comparison of intervention and control groups with respect to careseeking behaviour for reported child illness episodes during the six month follow up period. Values are number (percentage) of episodes unless otherwise stated

\begin{tabular}{|c|c|c|c|c|c|c|}
\hline \multirow[b]{2}{*}{ Careseeking behaviour } & \multirow[b]{2}{*}{ Intervention group } & \multirow[b]{2}{*}{ Control group } & \multicolumn{2}{|c|}{ Risk ratio } & \multirow{2}{*}{$\begin{array}{l}\text { Relative risk reduction }(\%) \S \\
(95 \% \mathrm{Cl})\end{array}$} & \multirow[b]{2}{*}{$P$ value } \\
\hline & & & Crude† & Adjusted $\neq$ & & \\
\hline All episodes of illness & $(\mathrm{n}=2851)$ & $(n=2654)$ & & & & \\
\hline Care not sought outside home & $509(18)$ & $497(19)$ & 0.97 & 0.98 & $2(-38$ to 30$)$ & 0.88 \\
\hline Care not sought from an appropriate provider & $1259(44)$ & $1315(50)$ & 0.90 & 0.90 & 10 (-27 to 36$)$ & 0.51 \\
\hline Prompt care* not sought from an appropriate provider & $2481(87)$ & $2433(92)$ & 0.95 & 0.96 & 4 (1 to 7$)$ & 0.02 \\
\hline Episodes with danger sign & $(n=543)$ & $(n=513)$ & & & & \\
\hline Care not sought outside home & $40(7)$ & $40(8)$ & 0.94 & 0.90 & $10(-35$ to 40$)$ & 0.58 \\
\hline Care not sought from an appropriate provider & $190(35)$ & $223(43)$ & 0.80 & 0.77 & 23 (4 to 38$)$ & 0.03 \\
\hline Prompt care* not sought from an appropriate provider & $459(85)$ & $462(90)$ & 0.94 & 0.95 & $5(-0.4$ to 11$)$ & 0.07 \\
\hline
\end{tabular}

*Prompt care=within 24 hours of mother noticing symptom.

†Risk ratio $=$ proportion of intervention mothers not practising recommended behaviour/proportion of control mothers not practising behaviour.

łAdjusted for age, caste, economic status, distance in minutes from the health facility, and maternal education when possible. For the last indicator (sought appropriate and prompt care),

adjusted for caste, economic status, and maternal education to achieve convergence.

$\S$ Relative risk reduction $=(1$-adjusted risk ratio $) \times 100 \%$.

ing of providers but also addressing systems issues such as efficient scheduling of field and administrative work in relation to clinical work and organisation of space and flow of patients in health facilities.

\section{Limitations of the study}

When interpreting the study findings, it should be remembered that we enrolled only mothers and children who had already sought care from a health facility at least once. Families who never seek care for their sick children at primary health centres might respond differently to counselling about care seeking. In addition, the repeated household visits for data collection may have influenced families' careseeking patterns in both study arms. In areas with higher levels of women's literacy and lower levels of poverty, such an intervention could lead to greater gains since families in such areas may be less constrained by factors such as distance and cost. More frequent exposure to educational messages through a wider range of channels may lead to greater changes in mothers' careseeking behaviour than we observed, and requires further investigation.

We thank Rajiv Bahl, AIIMs, New Delhi, for support and advice during all phases of the study; B D Gupta, D R Dabi, and Rajesh Mehta, who helped to adapt the training program; and Harish Chellani and Harish Kumar for conducting the training programme. The district health officials of Udaipur district provided invaluable support in implementing the project. We are grateful for the active interest and cooperation of the participant doctors,

\section{What is already known on this topic}

Counselling by trained providers can improve some key family practices for childcare such as feeding

Randomised trials to determine whether counselling can also improve care seeking have not been performed

\section{What this study adds}

Training doctors of rural primary health centres to counsel mothers on danger signs and when to seek prompt care can improve the mothers' appreciation of the need to seek care

The effect on mothers' careseeking behaviour is limited

Educational interventions to improve care seeking for childhood illnesses in different settings should be developed who often work in difficult situations, and for the hard work and sincerity of our field and data entry staff. We thank Liam Smeeth for helpful comments on a draft version of this paper.

Contributors: PM and JM conceptualised the study. PM, SDI, and KS supervised data collection and management and with JM monitored the implementation. SC and PM conducted the data analysis, and KS assisted in data analysis. PM, SC, SDI, and JM wrote and revised the manuscripts. PM is guarantor.

Funding: Division of Child and Adolescent Health, World Health Organisation, Geneva.

Competing interests: SC received salary support and travel costs from the department of child and adolescent health and development, WHO, to support his involvement in this work.

Ethical approval: Ethical committee of Action Research and Training for Health and WHO Secretariat Committee on Research Involving Human Subjects.

1 Sutrisna B, Reingold A, Kresno S, Harrison G, Utomo B. Care seeking for fatal illnesses in young children in Indramayu, West Java, Indonesia. Lancet 1993;342:787-9.

2 D' Souza RM. Role of health seeking behaviour in child mortality in the slums of Karachi, Pakistan. J Biosoc Sci 2003;35:131-44.

3 Reyes H, Perez-Cuevas R, Saleroom J, Tome P, Guiscafre H, Gutienez G. Infant mortality due to ARI: influence of primary care processes. Health Policy Plan 1997;12:214-23.

4 Desilva MWA, Wijekoon A, Hornik R, Martines J. Care seeking in Sri Lanka: one possible explanation for low childhood mortality. Soc Sci Med 2001;53:1363-72.

5 Jones G, Steketee RW, Black RE, Bhutta ZA, Morris SS, Bellagio Child Survival Study Group. How many child deaths can we prevent this year? Lancet 2003;362:65-71.

6 World Health Organization. Technical bases for the WHO recommendations on the management of pneumonia in children at first level health facilities. Geneva: WHO, 1991. (WHO/ARI/91.20.)

7 World Health Organization. Counsel the mother: management of childhood illnesses. Geneva: WHO, 1997.

8 Government of Rajasthan. Rajasthan human development report-2002. Jaipur: Government of Rajasthan, 2002.

9 World Health Organization, Division of Child Health and Development. Integrated management of childhood illness: adaptation guide. Working draft version 3. Geneva: WHO, 1997.

10 World Health Organization. Breastfeeding counselling: a training course. Geneva: WHO, 1993. (WHO/CDR/93.3, 4,5,6.)

$11 \mathrm{WHO} / \mathrm{CHD}$ Immunisation Linked Vitamin A Supplementation Study Group. Randomised trial to assess benefits and safety of vitamin A supplementation linked to immunisation in early infancy. Lancet 1998;352:1257-63.

12 Diehr P, Martin DC, Koepsell T, Cheadle A. Breaking the matches in a paired t-test for community interventions when the number of pairs is small. Stat Med 1995; 14:1491-504.

13 Miettinen O. Estimability and estimation in case-referent studies. Am J Epidemiol 1976;103:226-35.

14 Yoder PS, Hornik RC. Perception of severity of diarrhea and treatment choice: a comparative study of health com sites. J Trop Med Hyg 1994;97:1-12.

15 Goldman N, Pebley AR, Gragnolati M. Choices about treatment for ARI and diarrhoea in rural Guatemala. Soc Sci Med 2002;55:1693-71.

16 Atakouma DY, Gbetoglo D, Tursz A, Crost M, Agbere A, Assimadi JK. An epidemiological study of health care seeking behaviour by children under the age of 5 years at hospital emergency services in Togo. Rev Epidemiol Sante Publique 1999;47(suppl 2):75-91.

17 Tursz A, Crost M, Kermani S, Reghal M, Grangaud JP. An epidemiological study of health care seeking behaviour of children under 5 years of age in Algeria: what lessons for improving the health care system? Rev Epidemiol Sante Publique 1999;47(suppl 2):18-37. 
18 Herman E, Black RE, Wahba S, Khallaf N. Developing strategies to encourage appropriate care seeking for children with acute respiratory infections: an example from Egypt. Int J Health Plann Manage 1994;9:235-43.

19 Tupasi TE, Miguel CA, Tallo VL, Bagasao TM, Natividad JN, Valencia LB, et al. Childcare practices of mothers: implications for intervention in acute respiratory infections. Ann Trop Paediatr 1989;9:82-8.

20 Simoes EAF, Desta T, Tessema T, Gebresellassie, Dagnew M, Gove S. Performance of health workers after training in integrated management of childhood illness in Gondar, Ethiopia. Bull World Health Org 1997;75(suppl 1):43-53.

21 Santos I, Victora CG, Martines J, Goncalves H, Gigante DP, Valle NJ, et al. Nutrition counseling increases weight gain among Brazilian children. J Nutr 2001;131:2866-73.

(Accepted 13 May 2004)

doi $10.1136 /$ bmj. 38149.703380 .47
Child Health Program, Action Research and Training for Health (ARTH), 39 Fatehpura, Udaipur, India 313004

Pavitra Mohan coordinato

Sharad D Iyengar secretary

Kalpana Sen research associate

Department of Child and Adolescent Health and Development, World Health Organization, CH1211 Geneva, Switzerland

Jose Martines team coordinator

Department of Infectious and Tropical Diseases, London School of Hygiene and Tropical Medicine, London WC1E 7HT

Simon Cousens professor

Correspondence to: P Mohan pmohan@unicef.org 